Review

\title{
Abnormal Base Excision Repair at Trinucleotide Repeats Associated with Diseases: A Tissue-Selective Mechanism
}

\author{
Agathi-Vasiliki Goula and Karine Merienne * \\ Programme of Translational Medicine and Neurogenetics, Institute of Genetics and Molecular and \\ Cellular Biology (IGBMC), UMR 7104-CNRS/INSERM/Uds, 1 rue Laurent Fries, 67404 Illkirch, \\ France; E-Mail: agathi.goula@hotmail.fr
}

* Author to whom correspondence should be addressed; E-Mails: merienne@igbmc.fr; Tel.: +33-3-88-65-34-06; Fax: +33-3-88-65-32-46.

Received: 2 May 2013; in revised form: 25 June 2013 / Accepted: 26 June 2013 /

Published: 25 July 2013

\begin{abstract}
More than fifteen genetic diseases, including Huntington's disease, myotonic dystrophy 1, fragile $\mathrm{X}$ syndrome and Friedreich ataxia, are caused by the aberrant expansion of a trinucleotide repeat. The mutation is unstable and further expands in specific cells or tissues with time, which can accelerate disease progression. DNA damage and base excision repair (BER) are involved in repeat instability and might contribute to the tissue selectivity of the process. In this review, we will discuss the mechanisms of trinucleotide repeat instability, focusing more specifically on the role of BER.
\end{abstract}

Keywords: trinucleotide repeat diseases; instability; BER

\section{Trinucleotide Repeat Instability in Diseases}

Trinucleotide repeat (TNR) disorders define a group of more than fifteen neurodegenerative, neurological and neuromuscular diseases [1,2]. These genetic diseases result from the aberrant expansion of TNRs within specific genes. Various types of TNRs can cause diseases, including CAG repeats (Huntington's disease, HD, and several dominant spinocerebellar ataxia), CTG repeats (myotonic dystrophy 1, DM1), CGG repeats (fragile X syndrome, FXS) and GAA repeats (Friedreich ataxia, FRDA). Noticeably, CAG/CTG repeat diseases are the most frequent, accounting for a dozen of disorders. TNRs are polymorphic in the control population; however, above a threshold of 30 to 50 repeat units, the repeats are pathogenic. TNRs associated with diseases are found in various parts of 
genes, including 3 ' and 5' UTRs, exons and introns. The location of the repeat expansion within genes influences the pathomechanism, which ranges from loss-of-function (FXS, FRDA) and protein and RNA gain-of-functions (HD and DM1, respectively).

TNR expansions are dynamic mutations, which are ongoing across generations and within tissues, due to germline and somatic instability, respectively [3]. The outcome of repeat instability is contraction or expansion of the repeat. Expansion in the germline can lead to an anticipation effect, corresponding to worsening of the disease in successive generations, i.e., earlier onset and more rapid progression of the symptoms [4]. Depending on the disease, a parent-of-origin effect is observed, resulting in paternal or maternal bias of expansion or contraction. In somatic tissues, expansion events tend to be more frequent than contraction events, leading to the progressive increase of the repeat tract with age. Importantly, somatic instability is tissue-selective. In most TNR diseases, the degree of variation of the repeat tract over time is highly dependent upon tissue or cell-type, and the tissues or cells presenting high TNR instability vary to some extent between diseases [2]. In HD and DM1, somatic instability is most prevalent in the affected tissues and has been proposed to act as a disease modifier, accelerating disease progression [5-8]. In HD, CAG instability is most elevated in the striatum, the tissue that is most affected [6,9-13]. It is noteworthy that in most CAG/CTG diseases, repeat instability is generally elevated in brain tissues, with the exception of the cerebellum, which presents limited repeat instability [2]. Interestingly, somatic CAG instability is usually great in the central nervous system and, more specifically, in neurons, indicative of the implication of replication-independent mechanisms [6].

\section{Trinucleotide Repeat Instability as the Result of Erroneous DNA Repair}

Mechanistic models of TNR instability are based upon the assumption that TNRs form stable DNA secondary structures, and error-prone repair of those structures results in repeat size variation $[1,3,14]$. In vitro experiments have shown that TNR sequences can adopt several structures, and the sequence of the repeat influences both the stability and the nature of the DNA structure $[15,16]$. For instance, slipped-out CAG and slipped-out CTG repeats adopt predominantly random coil and hairpin conformation, respectively, which explains the increased stability of CTG-associated DNA structures relative to CAG-associated DNA structures [17-20]. In addition, increasing the length of TNRs augments the stability, as well as the complexity of the secondary structures [15,16,21]. Sequences of more than $10 \mathrm{CAG} / \mathrm{CTG}$ repeats can show a pattern involving multiple loops or hairpins [21,22]. An additional level of complexity of DNA structures is suggested by a recent study showing interconverting conformations of slipped-DNA junctions formed by TNRs [23]. Finally, stable DNA:RNA hybrids (R-loops) can also form during transcription across TNRs [24,25].

It remains to be determined whether unusual DNA:DNA structures truly form under physiological conditions, particularly in cells or tissues presenting high levels of repeat instability. However, several pieces of indirect evidence support their in vivo existence. Cellular processes altering DNA or chromatin structure, including DNA repair, replication, transcription and epigenetic-related mechanisms, have been shown to contribute to TNR instability [3]. These processes would either promote the formation of secondary structures at repeats or induce their error-prone repair. 
More specifically, studies performed using mice modeling DM1, HD, spinocerebellar ataxia type 7 and spinocerebellar ataxia type 1 indicate that the chromatin, transcription and replication status at repeats modulates repeat instability through gene-specific cis-elements, which include CCCTC-binding factor (CTCF) sites, $\mathrm{CpG}$ islands and replication origins [26-29]. It would remain to be examined whether the level of trans-factors regulating cis-element activity, including CTCF, modulate susceptibility to instability in tissues.

In addition, it has been shown that trans-factors involved in DNA repair are physiological modifiers of TNR instability. Specifically, in HD and/or DM1 mice, TNR instability is reduced upon inactivation of genes involved in mismatch repair (MMR), including Msh2, Msh3 and Pms2 [30-34], base excision repair (BER), including Oggl and Neil1 [35,36], and nucleotide excision repair (NER), including Xpa and $C s b$ [37,38]. Thus, abnormal repair at TNR promotes instability. How these different factors and mechanisms interplay in a given tissue is unclear, but it is likely that the contribution of each is dependent upon the tissue considered. Therefore, investigating the mechanisms underlying tissue-selectivity should help in deciphering TNR instability. Our recent data suggest that BER is one mechanism involved in the tissue selectivity of CAG/CTG repeat instability. Below, we discuss, more specifically, the physiological role of BER in the TNR instability associated with disease.

\section{In Vivo Mechanism of BER in Trinucleotide Repeat Instability}

BER is a DNA repair pathway specialized in the elimination of DNA base damage, of which 8-oxoguanine (8-oxoG) is the most common DNA lesion [39,40]. BER is characterized by a sequence of highly coordinated steps, starting from the removal of the DNA base lesion by a DNA glycosylase. This results in the formation of an abasic site, which is cleaved by an AP endonuclease (Ape1 in mammals) [41,42]. The DNA strand break is then processed by either single-nucleotide base excision repair (SN-BER) or long-patch base excision repair (LP-BER). In SN-BER, DNA polymerase $\beta$ (Pol $\beta$ ) incorporates a single nucleotide and incises the remaining 5'-sugar phosphate, prior to ligation by DNA ligase III (Lig3). In LP-BER, the flap endonuclease 1 (Fen1) removes the 5'-flap structure generated during the multi-nucleotide synthesis step mediated by Pol $\beta$ or a replicative DNA polymerase prior to ligation by DNA ligase I (Lig1) [41,42].

\subsection{BER in Various Models of Trinucleotide Repeat Instability}

Yeast studies demonstrated the first evidence that allowed insight into the involvement of BER proteins in TNR instability. Deficiency or haploinsufficiency of rad27, the homolog of mammalian Fen1 in yeast, led to length-dependent CAG/CTG expansion and instability $[43,44]$. On the other side, it is the overexpression of Lig1 homolog in yeast $(c d c 9)$ that yielded longer repeat tracts [45]. Overexpression of an inactive form of cdc9 possessing a functional binding site for proliferating cell nuclear antigen (PCNA) led to similar results, suggesting that instability is dependent upon PCNA interaction rather than DNA ligase activity $[45,46]$. Mutations in PCNA and the replicative DNA polymerase Pol $\delta$ also induced destabilization of the repeat tract [47]. Fen1, PCNA, Lig1 and the replicative DNA polymerases are involved in both replication and LP-BER, and yeast studies did not allow discriminating of whether replication and/or LP-BER contribute most to TNR instability. The effects of Lig1 protein level, activity and capacity to interact with PCNA on replication and repair at 
$\mathrm{CAG} / \mathrm{CTG}$ repeats were assessed using human cells and plasmid-based substrates [48]. Consistent with the yeast studies, disruption of Lig1 and PCNA interaction increased instability, due to errors during replication, whereas Lig1 overexpression increased repair-dependent TNR instability. In addition, reduced Lig1 activity did not alter instability.

Mouse genetics was further used to attempt to define the role of BER proteins in TNR instability. DM1 mice were crossed with knock-in mice carrying a mutation in Lig1, resulting in very low residual ligase activity [49,50]. Somatic CTG/CAG instability in DM1 mice expressing the Lig1 mutant was similar to that in DM1 mice. However, DM1 mice mutants for Lig1 showed a maternal instability bias, leading to increased contractions and decreased expansions. Furthermore, HD and DM1 mice were crossed with mice haploinsufficient for Fen1. Somatic CAG/CTG instability was unchanged in HD and DM1 mice heterozygous for Fenl, regardless of the tissues analyzed, though a modest effect on germline instability was observed in HD mice haploinsufficient for Fen1 [51,52]. These results might indicate that the mechanisms underlying CAG/CTG instability in yeast and mammals are different. The involvement of replication in repeat instability might be prominent in proliferative cells, such as yeast, but more limited in mammalian tissues. Alternatively, different compensatory mechanisms might take place in yeast and mammalian tissues that could account for the different effects induced by deficiency of Fen1 or Lig1 in the two model systems. Of note, in contrast to yeast, the complete inactivation of Fenl could not be achieved in mice, due to the embryonic lethality of full knock-outs [53,54]. In general, assessing the role of BER proteins in CAG/CTG instability using mouse genetics is a difficult task, as inactivation of the main BER genes, including Pol $\beta$ [55,56], Ape1 [57], Xrcc1 [58], Fen1 or Lig1, is embryonically lethal.

DNA glycosylases represent an exception to this rule. The inactivation of individual DNA glycosylases is compatible with life in mammals, due to functional redundancy. Interestingly, full inactivation of the DNA glycosylase, Oggl, in HD mice led to reduction of the age-dependent repeat instability in the brain and liver, suggesting the repair of 8-oxoG lesions promotes somatic CAG instability [35]. Inactivation of $\mathrm{Oggl}$ or Apel in a human cell model allowing for detection of repeat contraction events only did not improve repeat stability, possibly due to the low frequency rate of contraction in this model system [59]. In addition, HD mice deficient for the DNA glycosylases, Aag and Nthl, which remove alkylated purines and pyrimidine-derived lesions, respectively, had no effect on CAG instability [35]. In addition, somatic and germline instability was reduced in HD mice deficient for Neill. Interestingly, somatic instability was decreased in all tissues tested, which included brain and non-brain tissues. Neill is a DNA glycosylase that targets pyrimidine-derived lesions, like NTH1 [36]. However, Neill can remove DNA lesions in both duplex and single-strand DNA (ssDNA), and can also remove 8-oxoG lesions in both DNA configurations, though removal efficiency for this DNA lesion is poor [60]. Importantly, CAG instability in HD mice was only moderately reduced upon inactivation of Oggl and Neill, and phenotype penetrance (e.g., improved CAG instability) was partial, suggesting that neither Ogg1 nor Neill is essential regarding CAG instability, possibly due to overlapping substrate specificities. Whereas these data demonstrate that DNA glycosylases contribute to CAG instability in vivo, the exact nature of mutagenic DNA lesions remains elusive. Assessing the effect of inactivation of additional DNA glycosylases could help in answering this question. Finally, it remains to be determined whether DNA glycosylases contribute to repeat instability in other models of TNR diseases. Interestingly, it was reported that the DNA oxidizing agent, potassium bromate, 
exacerbates germline repeat expansion in a fragile $\mathrm{X}$ premutation model, suggesting that repair of oxidative DNA lesions might be involved in the instability of CGG repeats [61].

\subsection{Level and Accessibility of DNA Lesions at Trinucleotide Repeats}

Accumulation of oxidative DNA damage with age in specific tissues could explain the age dependency and tissue specificity of somatic instability [35]. However, though the global level of DNA damage increased with age in HD mouse striatum and cerebellum, it was lower in the striatum, which presents high CAG instability levels, when compared to the cerebellum, showing minimal repeat instability [62]. In addition, DNA damage at CAG repeats did not increase with age and was not higher in striatum, though it was abnormally high in HD mouse tissues [62]. These data suggest that the amount of DNA lesions at CAG repeats does not directly contribute to age-dependent and tissue-selective somatic instability, suggesting that other mechanisms explain these features.

The increased level of DNA lesions at CAG repeats found in tissues of HD mice might result from their reduced accessibility to DNA repair proteins. Several studies support this hypothesis. Repair of hairpin-forming substrates with DNA lesions, including 8-oxoG, 5-OHC and the AP site, was impeded, likely due to reduced binding of DNA repair proteins to hairpin structures [36,62-64]. Along this line, the degree of stiffness of CAG/CTG substrates with slip-outs negatively influenced repair efficiency [23]. Additionally, hairpin substrates with CAG/CTG repeats contained a hot spot for DNA damage [63]. Thus, both reduced accessibility and increased susceptibility to DNA damage could contribute to lesion accumulation at $\mathrm{CAG} / \mathrm{CTG}$ expansions.

\subsection{Mechanism of BER in Tissue-Selective CAG/CTG Repeat Instability}

Several in vitro and cell-based studies have provided insights into the mechanism by which BER proteins might contribute to $\mathrm{CAG} / \mathrm{CTG}$ instability. It has been reported that processing of $\mathrm{CAG} / \mathrm{CTG}$ substrates by Pol $\beta$, a central component of BER, leads to strand displacement and multi-nucleotide gap filling, due to polymerase slippage at repeats $[65,66]$. Polymerase slippage would induce the formation of a 5'-flap structure, which would require LP-BER proteins, including Fen1 and Lig1, for completion of repair. Since stable secondary structures forming at TNR repeats prevent efficient excision by Fen1 [67,68], it was hypothesized that expansion of the repeat tract could arise from inefficient excision or alternate cleavage by Fen1 of the 5'-flap structure generated upon multi-nucleotide gap filling by Pol $\beta$, followed by ligation of an erroneous number of repeats $[14,66]$. Alternate cleavage by Fen 1 would be required for the generation of a ligatable nick and completion of repair. Studies using partially and fully reconstituted repair assays support these possibilities and further indicate that the level of coordination of BER enzymatic steps is critical in determining the repair outcome at CAG/CTG repeats [69-71]. The processing of CAG/CTG substrates preferentially involved LP-BER in contrast to substrates with a random sequence, suggesting that LP-BER is required to repair a lesion at $\mathrm{CAG} / \mathrm{CTG}$ repeats. Furthermore, repair outcome was influenced by the stoichiometry of BER proteins $[62,71]$. BER protein levels and activities greatly varied between the striatum and the cerebellum. Although the level of Pol $\beta$ was similar in the two tissues, LP-BER proteins, including Fen1 and Lig1, were much more abundant in the cerebellum as compared to the striatum. As a result, repair efficiency at CAG/CTG repeats was poor and led to the formation of persistent intermediate 
products when using the striatal BER protein stoichiometry, as compared to that of the cerebellum. It was hypothesized that the sub-optimal BER activity in the striatum contributes to the increased striatal instability seen in HD, whereas the efficient and well-coordinated BER activity in the cerebellum might limit instability in this tissue, preventing the formation of secondary DNA structures at repeats.

Moreover, the sequence of the repeat (CAG versus $\mathrm{CTG}$ ) and the position of the lesion within the CAG/CTG substrates also influenced repair outcome, e.g., repair efficiency and LP-BER requirement [71,72]. The results by Lai et al. suggest that the position of the lesion within the repeat substrate determines whether expansion or contraction occurs [72]. It was reported that a lesion located at the 5'-end of CTG repeats results in expansion, whereas a lesion located in the middle or the 3'-end of the repeats results in deletion. In studies using plasmid-based CAG/CTG substrates and mammalian cell extracts, it was also reported that the position of a nick with respect to the repeat tract influences repair outcome $[18,20,22,73]$. In these assays, repair efficiency was decreased when the slip-out was located on the CTG strand in comparison to the CAG strand. The mechanism of TNR instability includes both stochastic and deterministic components [74]. The occurrence, accessibility and location of a DNA lesion at repeats are stochastic events that might contribute to the stochastic component of instability, whereas damage repair would be involved in the deterministic component. Since BER protein stoichiometry varies between tissues, this BER deterministic component might be tissue-dependent (Figure 1). Interestingly, the level of MMR proteins, including Msh2, Msh3 and Msh6, is also highly variable between mouse tissues [75]. It was suggested that the elevated levels of MMR proteins in embryonic stem cells of DM1 patients might contribute to the high CTG instability level found in these cells [76]. Similar conclusions were drawn using induced pluripotent stem cells derived from fibroblasts of Friedreich ataxia patients [77,78]. However, the relative levels of MMR proteins were higher in the cerebellum, as compared to the striatum and cortex, indicating that high MMR protein amounts do not correlate with high instability levels in somatic tissues. Further studies are required to specify how tissue-specific regulation of trans-factors impacts on tissue selective instability.

\section{Conclusions}

Many genetic diseases are caused by dynamic mutations, including trinucleotide repeat expansion diseases. Repeat instability can accelerate disease progression. Understanding the etiology of TNR instability is crucial, since instability might represent a therapeutic target. During the last decade, important advances have been made that increase our understanding of the rules governing this particular type of instability. Specifically, it was discovered that oxidative DNA damage and BER play a physiological role in the somatic CAG instability involved in HD and possibly contribute to the tissue selectivity and stochasticity of the instability process. Yet, how broad the involvement of oxidative DNA damage and BER in the TNR instability associated with diseases is would need to be investigated. How BER interacts with other mechanisms modulating TNR instability, including MMR, transcription and replication, is also a question that would deserve interest. 
Figure 1. Base excision repair (BER)-induced CAG repeat expansion is tissue-dependent. Oxidative DNA lesions, including 8-oxoG lesions, occur stochastically at trinucleotide CAG repeats and are processed by the BER pathway. A DNA glycosylase (e.g., Ogg1) and Ape1 initiate repair. Repair outcome ("no expansion" or "expansion") is dependent upon the location of the lesion and the tissue that is repaired. In the cerebellum, where Fen1 and Lig1 are abundant, the DNA lesion at CAG repeats is correctly repaired: the flappy structure resulting from multinucleotide incorporation by Pol $\beta$ during long-patch (LP)-BER by Fen 1 is efficiently processed, and the subsequent ligation step does not result in expansion. In contrast, in the striatum, where Fen1 and Lig1 proteins are reduced, repair of the DNA lesion at CAG repeats is error-prone. The flappy structure is not efficiently processed, which ultimately leads to repeat expansion through a yet unknown mechanism. Additional DNA repair pathways, including mismatch repair (MMR), might interplay with BER during this process.

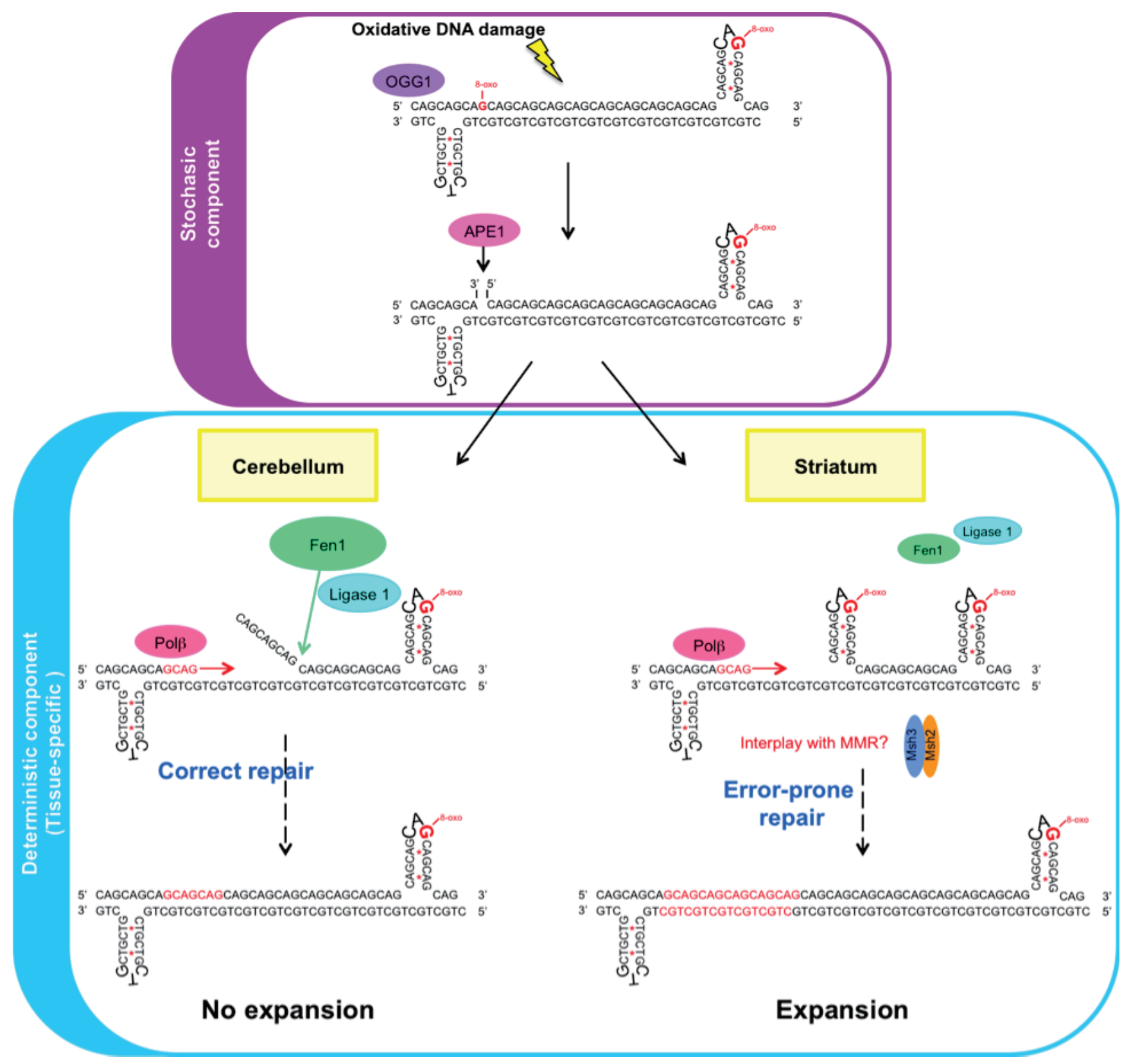




\section{Acknowledgements}

These studies were supported by the Centre National de la Recherche Scientifique (CNRS), the Institut National de la Santé et de la Recherche Médicale (INSERM), the University of Strasbourg and by a grant from the French Agence Nationale de la Recherche (ANR-2011-JSV6-003-01).

\section{Conflict of Interest}

The authors declare no conflict of interest.

\section{References}

1. Mirkin, S.M. Expandable DNA repeats and human disease. Nature 2007, 447, 932-940.

2. Pearson, C.E.; Nichol Edamura, K.; Cleary, J.D. Repeat instability: Mechanisms of dynamic mutations. Nat. Rev. Genet. 2005, 6, 729-742.

3. Lopez Castel, A.; Cleary, J.D.; Pearson, C.E. Repeat instability as the basis for human diseases and as a potential target for therapy. Nat. Rev. Mol. Cell Biol. 2010, 11, 165-170.

4. Pearson, C.E. Slipping while sleeping? Trinucleotide repeat expansions in germ cells. Trends Mol. Med. 2003, 9, 490-495.

5. Gonitel, R.; Moffitt, H.; Sathasivam, K.; Woodman, B.; Detloff, P.J.; Faull, R.L.; Bates, G.P. DNA instability in postmitotic neurons. Proc. Natl. Acad. Sci. USA 2008, 105, 3467-3472.

6. Shelbourne, P.F.; Keller-McGandy, C.; Bi, W.L.; Yoon, S.R.; Dubeau, L.; Veitch, N.J.; Vonsattel, J.P.; Wexler, N.S.; Arnheim, N.; Augood, S.J. Triplet repeat mutation length gains correlate with cell-type specific vulnerability in huntington disease brain. Hum. Mol. Genet. 2007, $16,1133-1142$.

7. Swami, M.; Hendricks, A.E.; Gillis, T.; Massood, T.; Mysore, J.; Myers, R.H.; Wheeler, V.C. Somatic expansion of the huntington's disease cag repeat in the brain is associated with an earlier age of disease onset. Hum. Mol. Genet. 2009, 18, 3039-3047.

8. Morales, F.; Couto, J.M.; Higham, C.F.; Hogg, G.; Cuenca, P.; Braida, C.; Wilson, R.H.; Adam, B.; del Valle, G.; Brian, R.; et al. Somatic instability of the expanded ctg triplet repeat in myotonic dystrophy type 1 is a heritable quantitative trait and modifier of disease severity. Hum. Mol. Genet. 2012, 21, 3558-3567.

9. Chong, S.S.; McCall, A.E.; Cota, J.; Subramony, S.H.; Orr, H.T.; Hughes, M.R.; Zoghbi, H.Y. Gametic and somatic tissue-specific heterogeneity of the expanded scal cag repeat in spinocerebellar ataxia type 1. Nat. Genet. 1995, 10, 344-350.

10. Hashida, H.; Goto, J.; Suzuki, T.; Jeong, S.; Masuda, N.; Ooie, T.; Tachiiri, Y.; Tsuchiya, H.; Kanazawa, I. Single cell analysis of cag repeat in brains of dentatorubral-pallidoluysian atrophy (drpla). J. Neurol. Sci. 2001, 190, 87-93.

11. Kennedy, L.; Shelbourne, P.F. Dramatic mutation instability in hd mouse striatum: Does polyglutamine load contribute to cell-specific vulnerability in huntington's disease? Hum. Mol. Genet. 2000, 9, 2539-2544. 
12. Lopes-Cendes, I.; Maciel, P.; Kish, S.; Gaspar, C.; Robitaille, Y.; Clark, H.B.; Koeppen, A.H.; Nance, M.; Schut, L.; Silveira, I.; et al. Somatic mosaicism in the central nervous system in spinocerebellar ataxia type 1 and machado-joseph disease. Ann. Neurol. 1996, 40, 199-206.

13. Telenius, H.; Kremer, B.; Goldberg, Y.P.; Theilmann, J.; Andrew, S.E.; Zeisler, J.; Adam, S.; Greenberg, C.; Ives, E.J.; Clarke, L.A.; et al. Somatic and gonadal mosaicism of the huntington disease gene cag repeat in brain and sperm. Nat. Genet. 1994, 6, 409-414.

14. McMurray, C.T. Mechanisms of trinucleotide repeat instability during human development. Nat. Rev. Genet. 2010, 11, 786-799.

15. Gacy, A.M.; Goellner, G.; Juranic, N.; Macura, S.; Mcmurray, C.T. Trinucleotide repeats that expand in human disease form hairpin structures in vitro. Cell 1995, 81, 533-540.

16. Pearson, C.E.; Sinden, R.R. Alternative structures in duplex DNA formed within the trinucleotide repeats of the myotonic dystrophy and fragile x loci. Biochemistry 1996, 35, 5041-5053.

17. Pearson, C.E.; Tam, M.; Wang, Y.H.; Montgomery, S.E.; Dar, A.C.; Cleary, J.D.; Nichol, K. Slipped-strand dnas formed by long (cag)*(ctg) repeats: Slipped-out repeats and slip-out junctions. Nucleic Acids Res. 2002, 30, 4534-4547.

18. Hou, C.; Chan, N.L.; Gu, L.; Li, G.M. Incision-dependent and error-free repair of (cag)(n)/(ctg)(n) hairpins in human cell extracts. Nat. Struct. Mol. Biol. 2009, 16, 869-875.

19. Mitas, M.; Yu, A.; Dill, J.; Kamp, T.J.; Chambers, E.J.; Haworth, I.S. Hairpin properties of single-stranded DNA containing a gc-rich triplet repeat: (ctg)15. Nucleic Acids Res. 1995, 23, 1050-1059.

20. Panigrahi, G.B.; Lau, R.; Montgomery, S.E.; Leonard, M.R.; Pearson, C.E. Slipped (ctg)*(cag) repeats can be correctly repaired, escape repair or undergo error-prone repair. Nat. Struct. Mol. Biol. 2005, 12, 654-662.

21. Pearson, C.E.; Wang, Y.H.; Griffith, J.D.; Sinden, R.R. Structural analysis of slipped-strand DNA (s-DNA) formed in (ctg)n. (cag)n repeats from the myotonic dystrophy locus. Nucleic Acids Res. 1998, 26, 816-823.

22. Panigrahi, G.B.; Slean, M.M.; Simard, J.P.; Gileadi, O.; Pearson, C.E. Isolated short ctg/cag DNA slip-outs are repaired efficiently by hmutsbeta, but clustered slip-outs are poorly repaired. Proc. Natl. Acad. Sci. USA 2010, 107, 12593-12598.

23. Slean, M.M.; Reddy, K.; Wu, B.; Nichol Edamura, K.; Kekis, M.; Nelissen, F.H.; Aspers, R.L.; Tessari, M.; Scharer, O.D.; Wijmenga, S.S.; et al. Interconverting conformations of slipped-DNA junctions formed by trinucleotide repeats affect repair outcome. Biochemistry 2013, 52, 773-785.

24. Reddy, K.; Tam, M.; Bowater, R.P.; Barber, M.; Tomlinson, M.; Nichol Edamura, K.; Wang, Y.H.; Pearson, C.E. Determinants of r-loop formation at convergent bidirectionally transcribed trinucleotide repeats. Nucleic Acids Res. 2010, 39, 1749-1762.

25. Lin, Y.; Dent, S.Y.; Wilson, J.H.; Wells, R.D.; Napierala, M. R loops stimulate genetic instability of ctg.Cag repeats. Proc. Natl. Acad. Sci. USA 2010, 107, 692-697.

26. Libby, R.T.; Hagerman, K.A.; Pineda, V.V.; Lau, R.; Cho, D.H.; Baccam, S.L.; Axford, M.M.; Cleary, J.D.; Moore, J.M.; Sopher, B.L.; et al. Ctcf cis-regulates trinucleotide repeat instability in an epigenetic manner: A novel basis for mutational hot spot determination. PLoS Genet. 2008, 4, e1000257. 
27. Dion, V.; Lin, Y.; Hubert, L., Jr.; Waterland, R.A.; Wilson, J.H. Dnmt1 deficiency promotes cag repeat expansion in the mouse germline. Hum. Mol. Genet. 2008, 17, 1306-1317.

28. Cleary, J.D.; Tome, S.; Lopez Castel, A.; Panigrahi, G.B.; Foiry, L.; Hagerman, K.A.; Sroka, H.; Chitayat, D.; Gourdon, G.; Pearson, C.E. Tissue- and age-specific DNA replication patterns at the ctg/cag-expanded human myotonic dystrophy type 1 locus. Nat. Struct. Mol. Biol. 2010, 17, 1079-1087.

29. Dion, V.; Wilson, J.H. Instability and chromatin structure of expanded trinucleotide repeats. Trends Genet. 2009, 25, 288-297.

30. Dragileva, E.; Hendricks, A.; Teed, A.; Gillis, T.; Lopez, E.T.; Friedberg, E.C.; Kucherlapati, R.; Edelmann, W.; Lunetta, K.L.; MacDonald, M.E.; et al. Intergenerational and striatal cag repeat instability in huntington's disease knock-in mice involve different DNA repair genes. Neurobiol. Dis. 2009, 33, 37-47.

31. Wheeler, V.C.; Lebel, L.A.; Vrbanac, V.; Teed, A.; te Riele, H.; MacDonald, M.E. Mismatch repair gene msh2 modifies the timing of early disease in hdh(q111) striatum. Hum. Mol. Genet. 2003, 12, 273-281.

32. Manley, K.; Shirley, T.L.; Flaherty, L.; Messer, A. Msh2 deficiency prevents in vivo somatic instability of the cag repeat in huntington disease transgenic mice. Nat. Genet. 1999, 23, 471-473.

33. Savouret, C.; Garcia-Cordier, C.; Megret, J.; te Riele, H.; Junien, C.; Gourdon, G. Msh2-dependent germinal ctg repeat expansions are produced continuously in spermatogonia from $\mathrm{dm} 1$ transgenic mice. Mol. Cell. Biol. 2004, 24, 629-637.

34. Van den Broek, W.J.; Nelen, M.R.; Wansink, D.G.; Coerwinkel, M.M.; te Riele, H.; Groenen, P.J.; Wieringa, B. Somatic expansion behaviour of the (ctg)n repeat in myotonic dystrophy knock-in mice is differentially affected by msh3 and msh6 mismatch-repair proteins. Hum. Mol. Genet. 2002, 11, 191-198.

35. Kovtun, I.V.; Liu, Y.; Bjoras, M.; Klungland, A.; Wilson, S.H.; McMurray, C.T. Ogg1 initiates age-dependent cag trinucleotide expansion in somatic cells. Nature 2007, 447, 447-452.

36. Mollersen, L.; Rowe, A.D.; Illuzzi, J.L.; Hildrestrand, G.A.; Gerhold, K.J.; Tveteras, L.; Bjolgerud, A.; Wilson, D.M., 3rd; Bjoras, M.; Klungland, A. Neill is a genetic modifier of somatic and germline cag trinucleotide repeat instability in r6/1 mice. Hum. Mol. Genet. 2012, 21, 4939-4947.

37. Hubert, L., Jr.; Lin, Y.; Dion, V.; Wilson, J.H. Xpa deficiency reduces cag trinucleotide repeat instability in neuronal tissues in a mouse model of sca1. Hum. Mol. Genet. 2011, 20, 4822-4830.

38. Kovtun, I.V.; Johnson, K.O.; McMurray, C.T. Cockayne syndrome b protein antagonizes ogg1 in modulating cag repeat length in vivo. Aging 2011, 3, 509-514.

39. Lindahl, T. Instability and decay of the primary structure of DNA. Nature 1993, 362, 709-715.

40. Lindahl, T. Suppression of spontaneous mutagenesis in human cells by DNA base excision-repair. Mutat. Res. 2000, 462, 129-135.

41. Robertson, A.B.; Klungland, A.; Rognes, T.; Leiros, I. DNA repair in mammalian cells: Base excision repair: The long and short of it. Cell Mol. Life Sci. 2009, 66, 981-993.

42. Fortini, P.; Dogliotti, E. Base damage and single-strand break repair: Mechanisms and functional significance of short- and long-patch repair subpathways. DNA Repair 2007, 6, 398-409. 
43. Freudenreich, C.H.; Kantrow, S.M.; Zakian, V.A. Expansion and length-dependent fragility of ctg repeats in yeast. Science 1998, 279, 853-856.

44. Yang, J.; Freudenreich, C.H. Haploinsufficiency of yeast fen1 causes instability of expanded cag/ctg tracts in a length-dependent manner. Gene 2007, 393, 110-115.

45. Subramanian, J.; Vijayakumar, S.; Tomkinson, A.E.; Arnheim, N. Genetic instability induced by overexpression of DNA ligase i in budding yeast. Genetics 2005, 171, 427-441.

46. Refsland, E.W.; Livingston, D.M. Interactions among DNA ligase i, the flap endonuclease and proliferating cell nuclear antigen in the expansion and contraction of cag repeat tracts in yeast. Genetics 2005, 171, 923-934.

47. Schweitzer, J.K.; Livingston, D.M. The effect of DNA replication mutations on cag tract stability in yeast. Genetics 1999, 152, 953-963.

48. Lopez Castel, A.; Tomkinson, A.E.; Pearson, C.E. Ctg/cag repeat instability is modulated by the levels of human DNA ligase $\mathrm{i}$ and its interaction with proliferating cell nuclear antigen: A distinction between replication and slipped-DNA repair. J. Biol. Chem. 2009, 284, 26631-26645.

49. Harrison, C.; Ketchen, A.M.; Redhead, N.J.; O’Sullivan, M.J.; Melton, D.W. Replication failure, genome instability, and increased cancer susceptibility in mice with a point mutation in the DNA ligase i gene. Cancer Res. 2002, 62, 4065-4074.

50. Tome, S.; Panigrahi, G.B.; Lopez Castel, A.; Foiry, L.; Melton, D.W.; Gourdon, G.; Pearson, C.E. Maternal germline-specific effect of DNA ligase i on ctg/cag instability. Hum. Mol. Genet. 2011, 20, 2131-2143.

51. Spiro, C.; McMurray, C.T. Nuclease-deficient fen-1 blocks rad51/brca1-mediated repair and causes trinucleotide repeat instability. Mol. Cell. Biol. 2003, 23, 6063-6074.

52. Van den Broek, W.J.; Nelen, M.R.; van der Heijden, G.W.; Wansink, D.G.; Wieringa, B. Fen1 does not control somatic hypermutability of the $(\operatorname{ctg})(n) *(\operatorname{cag})(n)$ repeat in a knock-in mouse model for dm1. FEBS Lett. 2006, 580, 5208-5214.

53. Bentley, D.; Selfridge, J.; Millar, J.K.; Samuel, K.; Hole, N.; Ansell, J.D.; Melton, D.W. DNA ligase $\mathrm{i}$ is required for fetal liver erythropoiesis but is not essential for mammalian cell viability. Nat. Genet. 1996, 13, 489-491.

54. Kucherlapati, M.; Yang, K.; Kuraguchi, M.; Zhao, J.; Lia, M.; Heyer, J.; Kane, M.F.; Fan, K.; Russell, R.; Brown, A.M.; et al. Haploinsufficiency of flap endonuclease (fen1) leads to rapid tumor progression. Proc. Natl. Acad. Sci. USA 2002, 99, 9924-9929.

55. Cabelof, D.C.; Guo, Z.; Raffoul, J.J.; Sobol, R.W.; Wilson, S.H.; Richardson, A.; Heydari, A.R. Base excision repair deficiency caused by polymerase beta haploinsufficiency: Accelerated DNA damage and increased mutational response to carcinogens. Cancer Res. 2003, 63, 5799-5807.

56. Sobol, R.W.; Horton, J.K.; Kuhn, R.; Gu, H.; Singhal, R.K.; Prasad, R.; Rajewsky, K.; Wilson, S.H. Requirement of mammalian DNA polymerase-beta in base-excision repair. Nature 1996, 379, 183-186.

57. Xanthoudakis, S.; Smeyne, R.J.; Wallace, J.D.; Curran, T. The redox/DNA repair protein, ref-1, is essential for early embryonic development in mice. Proc. Natl. Acad. Sci. USA 1996, 93, 8919-8923.

58. Tebbs, R.S.; Flannery, M.L.; Meneses, J.J.; Hartmann, A.; Tucker, J.D.; Thompson, L.H.; Cleaver, J.E.; Pedersen, R.A. Requirement for the xrcc1 DNA base excision repair gene during early mouse development. Dev. Biol. 1999, 208, 513-529. 
59. Lin, Y.; Wilson, J.H. Transcription-induced cag repeat contraction in human cells is mediated in part by transcription-coupled nucleotide excision repair. Mol. Cell. Biol. 2007, 27, 6209-6217.

60. Dou, H.; Mitra, S.; Hazra, T.K. Repair of oxidized bases in DNA bubble structures by human DNA glycosylases neill and neil2. J. Biol. Chem. 2003, 278, 49679-49684.

61. Entezam, A.; Lokanga, A.R.; Le, W.; Hoffman, G.; Usdin, K. Potassium bromate, a potent DNA oxidizing agent, exacerbates germline repeat expansion in a fragile x premutation mouse model. Hum. Mutat. 2010, 31, 611-616.

62. Goula, A.V.; Berquist, B.R.; Wilson, D.M., 3rd; Wheeler, V.C.; Trottier, Y.; Merienne, K. Stoichiometry of base excision repair proteins correlates with increased somatic cag instability in striatum over cerebellum in huntington's disease transgenic mice. PLoS Genet. 2009, 5, e1000749.

63. Jarem, D.A.; Wilson, N.R.; Delaney, S. Structure-dependent DNA damage and repair in a trinucleotide repeat sequence. Biochemistry 2009, 48, 6655-6663.

64. Jarem, D.A.; Wilson, N.R.; Schermerhorn, K.M.; Delaney, S. Incidence and persistence of 8-oxo-7,8-dihydroguanine within a hairpin intermediate exacerbates a toxic oxidation cycle associated with trinucleotide repeat expansion. DNA Repair 2011, 10, 887-896.

65. Hartenstine, M.J.; Goodman, M.F.; Petruska, J. Weak strand displacement activity enables human DNA polymerase beta to expand cag/ctg triplet repeats at strand breaks. J. Biol. Chem. 2002, 277, 41379-41389.

66. Liu, Y.; Wilson, S.H. DNA base excision repair: A mechanism of trinucleotide repeat expansion. Trends Biochem. Sci. 2012, 37, 162-172.

67. Spiro, C.; Pelletier, R.; Rolfsmeier, M.L.; Dixon, M.J.; Lahue, R.S.; Gupta, G.; Park, M.S.; Chen, X.; Mariappan, S.V.; McMurray, C.T. Inhibition of fen-1 processing by DNA secondary structure at trinucleotide repeats. Mol. Cell 1999, 4, 1079-1085.

68. Vallur, A.C.; Maizels, N. Complementary roles for exonuclease 1 and flap endonuclease 1 in maintenance of triplet repeats. J. Biol. Chem. 2010, 285, 28514-28519.

69. Liu, Y.; Prasad, R.; Beard, W.A.; Hou, E.W.; Horton, J.K.; McMurray, C.T.; Wilson, S.H. Coordination between polymerase beta and fen1 can modulate cag repeat expansion. J. Biol. Chem. 2009, 284, 28352-28366.

70. Liu, Y.; Prasad, R.; Wilson, S.H. Hmgb1: Roles in base excision repair and related function. Biochim. Biophys. Acta 2010, 1799, 119-130.

71. Goula, A.V.; Pearson, C.E.; Della Maria, J.; Trottier, Y.; Tomkinson, A.E.; Wilson, D.M., 3rd; Merienne, K. The nucleotide sequence, DNA damage location, and protein stoichiometry influence the base excision repair outcome at cag/ctg repeats. Biochemistry 2012, 51, 3919-3932.

72. Lai, Y.; Xu, M.; Zhang, Z.; Liu, Y. Instability of ctg repeats is governed by the position of a DNA base lesion through base excision repair. PLoS One 2013, 8, e56960.

73. Hou, C.; Zhang, T.; Tian, L.; Huang, J.; Gu, L.; Li, G.M. The role of xpg in processing (cag)n/(ctg)n DNA hairpins. Cell. Biosci. 2011, 1, 11.

74. Higham, C.F.; Morales, F.; Cobbold, C.A.; Haydon, D.T.; Monckton, D.G. High levels of somatic DNA diversity at the myotonic dystrophy type 1 locus are driven by ultra-frequent expansion and contraction mutations. Hum. Mol. Genet. 2012, 21, 2450-2463. 
75. Tome, S.; Simard, J.P.; Slean, M.M.; Holt, I.; Morris, G.E.; Wojciechowicz, K.; te Riele, H.; Pearson, C.E. Tissue-specific mismatch repair protein expression: Msh3 is higher than msh6 in multiple mouse tissues. DNA Repair 2013, 12, 46-52.

76. Seriola, A.; Spits, C.; Simard, J.P.; Hilven, P.; Haentjens, P.; Pearson, C.E.; Sermon, K. Huntington's and myotonic dystrophy hescs: Down-regulated trinucleotide repeat instability and mismatch repair machinery expression upon differentiation. Hum. Mol. Genet. 2011, 20, 176-185.

77. Hick, A.; Wattenhofer-Donze, M.; Chintawar, S.; Tropel, P.; Simard, J.P.; Vaucamps, N.; Gall, D.; Lambot, L.; Andre, C.; Reutenauer, L.; et al. Induced pluripotent stem cell derived neurons and cardiomyocytes as a model for mitochondrial defects in friedreich's ataxia. Dis. Model. Mech. 2012, 7, doi:10.1242/dmm.010900.

78. Du, J.; Campau, E.; Soragni, E.; Ku, S.; Puckett, J.W.; Dervan, P.B.; Gottesfeld, J.M. Role of mismatch repair enzymes in gaa.Ttc triplet-repeat expansion in friedreich ataxia induced pluripotent stem cells. J. Biol. Chem. 2012, 287, 29861-29872.

(C) 2013 by the authors; licensee MDPI, Basel, Switzerland. This article is an open access article distributed under the terms and conditions of the Creative Commons Attribution license (http://creativecommons.org/licenses/by/3.0/). 